\title{
Support-nets: A participative action- research into the value of a mutual support group to overcome social isolation
}

\author{
Jenny Zwijnenburg ${ }^{1}$, Tine van Regenmortel ${ }^{2}$, René Schalk ${ }^{3}$
}

\begin{abstract}
Social isolation is a widespread problem with which community oriented social workers are increasingly confronted. Mutual support groups can be used by social workers to support socially isolated people. This paper reports on a participatory action research into the method Support-nets. In this method, a mutual support group is set up specifically for people that share the problem of social isolation. The aim of the study was to gain insight in how participants and social workers give substance to mutual support to overcome structural social isolation. Results show that in a Support-net, every participant is enabled to actively contribute. This makes participants feel that they are valued members of a social group. Based on this shared identity, people offer each other different types of social support, thus alleviating their isolation.
\end{abstract}

Keywords: social isolation; mutual support groups; empowerment; social work

1. Science practitioner, TRANZO, Tilburg School of Social and Behavioral Sciences, Tilburg University, The Netherlands

2. Professor Social Work, TRANZO Tilburg School of Social and Behavioral Sciences, Tilburg University, The Netherlands and HIVA and Faculty of Social Sciences, University of Leuven, Belgium

3. Professor Human Resource Management, Faculty of Economic and Management Sciences, North West University, Potchefstroom, South Africa and TRANZO,HRS, Tilburg School of Social and Behavioral Sciences, Tilburg University, The Netherland

Address for correspondence: Jenny.zwijnenburg@gmail.com

Date of first (online) publication lat April 2021 


\section{Introduction}

Social isolation is a growing problem in Western society that could reach epidemic proportions in the upcoming years (Linehan et al., 2014). In the Netherlands, more than 600.000 people are socially isolated, accounting for 3,5\% of the population (Coumans, 2016). This percentage is significantly higher among vulnerable groups, such as people with disabilities and people that suffer from chronic psychiatric conditions (Elishia, Casting, \& Hocking, 2006; Deacon et al., 2019).

Social isolation is undeniably a social problem and therefore falls within the scope of social workers' activities. There are a variety of social work interventions that aim to alleviate loneliness and social isolation. In the Netherlands, an inventory was made of 41 interventions (Van de Westelaken, 2012). It is remarkable that in almost all of these interventions, social isolation is treated as an individual problem. From this rationale, individual help is offered such as a social skills training or weekly visits by a volunteer.

Although these interventions provide relief for some, there are three problems with this approach. In the first place, social isolation is not solely an individual problem. There is also a systemic component to social isolation that social workers should address (Van Regenmortel, 2009). Secondly, it will be difficult to reach people with problem-oriented interventions, because admitting that you are lonely is a taboo (Nicolaisen \& Thorsen, 2014). In the third place, most people do not want to be only a receiver of help (Uehara, 1995). Not being able to give something back can inhibit people in engaging in social relationships (Linders, 2010).

This paper focuses on this third problem. We know that reciprocity is important in targeting social isolation (Ten Bruggencate, Luijkx \& Sturm, 2018). Providing opportunities for reciprocal contact between socially isolated people can be a way to get a more positive outcome in interventions. One way social workers can enable this kind of contact, is by creating mutual support groups (MSGs) (LeCroy, 2014). MSGs are in line with what we know to be effective in targeting social isolation. In the first place, we know (Dickens et al., 2011) that interventions in which people participate actively are more effective. Secondly, we know that supporting relationships mainly emerge between people in similar situations (Linders, 2010). In the third place, we know that group interventions are more effective in targeting social isolation than individual support (Dickens et al., 2011).

A considerable amount of research has been conducted into the impact of peer support on social isolation (for example, Schutt \& Rogers, 2009; Solomon, 2004). However, research has thus far been focused on MSGs wherein people share a specific disease or problem (e.g., Kessler, Egan \& Kubina, 2014). Less attention has been paid to how social workers can effectively create community based MSGs specifically aimed at people who share the problem of social isolation.

The aim of this paper is to show how a method that puts this type of MSG into practice works: Support-nets (Vangnetwerken in Dutch). In a Support-net, social 
workers create a community-based mutual support group with and for people that are socially isolated. This paper reports on a participatory action research that was carried out in the period 2016-2017. The case-study focuses on the mutual support that is provided by participants in the Support-net in Rotterdam, the main question being:

How do participants and social workers give substance to mutual support in Supportnets to target social isolation?

The structure of this article is as follows: Firstly, the issue of social isolation and the possible value of mutual support is explored. After that the setting of the Support-net will be described. This is followed by a description of the research method, the results and the discussion.

\section{Theory}

\section{Definition, consequences and persistence of social isolation}

In this article, the definition of Machielse (2015) is used. She defines social isolation as 'A lack of personal relationships with family, friends and acquaintances on which people can fall back in case of need' (2015, p. 399).

In this definition, social isolation is an objective situation, namely lack of social support. This differs from the concept of loneliness, which emphasizes the subjective dimension of the quality of social relationships (Nicolaisen \& Thorsen, 2014). There is overlap between the concepts, however. Most people who are socially isolated experience strong feelings of loneliness. Hortulanus, Machielse, and Meeuwesen (2003) identify three types of support: instrumental support, emotional support, and companionship. People who are socially isolated have no access to one of more of these support types.

There are many negative consequences of social isolation. It reduces quality of life and it can lead to a variety of health issues (ten Bruggencate, Luijkx, \& Sturm, 2018). Social isolation is a strong predictor for depression (Cruwys et al., 2013). One meta-analysis (Holt-Lunstad et al., 2015) shows that social isolation increases mortality rates, and the authors state that this problem belongs on the list of wellknown risk factors of mortality like obesity and a sedentary lifestyle.

Social isolation can be temporary, resulting from illness, unemployment, or a divorce. But for a considerable number of people, social isolation is a structural problem (Machielse, 2015). When looking into the life history of people who are structurally isolated, often a combination is found of negative life events associated with loss (Deacon et al., 2019) and long-time existing problems in social relationships. 
According to Machielse (2006), people in individualised Western societies need to have strong social skills to build and maintain relationships. These skills are oftentimes lacking in socially isolated individuals. When people try to build relationships using inadequate social patterns, their efforts are reciprocated with negative responses.

Van Regenmortel (2009, p. 29) points to the significance of 'broken or non-existent social ties'. This leads to profound loneliness and the feeling of being excluded from society. Both Machielse (2015) and Van Regenmortel (2009) state that people eventually distance themselves from their social context. They become hesitant to undertake action to improve their lives. They have lost hope that their life can improve and are fearful that they will get hurt again.

2.2 Targeting social isolation with mutual support

The re-creation of ties to others is central to overcome social isolation. This can be viewed as an empowerment process which social workers can support. In this process, the socially isolated individual must take an active role (Van Regenmortel, 2009). For socially isolated people this means that they must find the courage to change their behaviour from passive resignation to actively trying to change their situation (Machielse (2006). They have to take the challenging but necessary step, to engage with other people again. This is essential to reverse their negative spiral of isolation.

The support that social workers offer should have both an individual as well as a systemic component (Rappaport, 1987; Van Regenmortel, 2009)). In individual help from an empowerment perspective social workers support people to find and mobilise their strengths to overcome the negative aspects of their situation. Social workers should also strive to make changes in society to make it possible for people with poor social competences to rejoin. A good place to start is to create contexts where social contacts can successfully take place, even for people with inadequate social skills. MSGs in social work provide a promising setting (LeCroy, 2014).

MSGs that focus specifically on socially isolated people can have multiple advantages. In the first place, they offer a safe setting for people to practice their social skills (Schutt $\&$ Rogers, 2009) and to have positive experiences in contact with others. These successful experiences will strengthen participants' selfconfidence (Van Regenmortel, 2009). Secondly, participating in a MSG increases the number of persons participants can turn to for social support (Solomon, 2004). A third advantage is that these groups offer opportunities for people to contribute actively and to engage in equal reciprocal relations (Steinberg, 2010), in which participants can experience that they are able to help other people: the power of giving (Van Regenmortel, 2009). 


\section{Support-nets}

A Support-net is a MSG specifically aimed at targeting social isolation. The method was developed in 2015 in the Dutch city of Rotterdam. A Support-net consists of 15-40 participants.

Participants meet each other weekly in a community centre. With the support of social workers, they organise recreational and educational activities for each other. Activities take shape based on the talents and wishes of the participants. For example, the Support-net in Rotterdam organises a computer group, a weekly lunch and a variety of creative activities. In addition to organising activities for each other, the Support-net reaches out to the surrounding community. One example is a project by which the Support-net collects second-hand baby clothes to distribute to pregnant women with financial problems.

\section{Research Method}

Both the participants and the social workers had the wish to make the way they work together more explicit. They wanted to combine their practical experience with scientific knowledge (Julkunen, 2011). In 2016-2017, one of the social workers decided to take on the role of researcher. She started working as a science practitioner at Tranzo, Tilburg University, The Netherlands.

The aim of the study was to examine the workings of the mutual support at Support-nets as well as to become aware of opportunities to improve current practice. Because of this dual purpose, the participative action research method 'exemplarian action research' (Coenen $\&$ Khonraad, 2003) was chosen. In action research, it is assumed that intervention and research are connected. This combines the pursuit of knowledge development (to prove) with the pursuit of improving the position of vulnerable citizens (to improve) (Author, 2016).

\section{Exemplarian action research}

In exemplarian action research, participants (in this case, participants of the Support-net) are closely involved in shaping and conducting the research. Researcher and researched jointly reflect as co-researchers on the practices of the researched (Coenen $\&$ Khonraad, 2003). The relationship between researcher and researched is based on reciprocal equality (Almekinders, Beukema, \& Tromp, 2009). For the researched, participating in the research process should be an 'empowering experience' (Van Regenmortel, 2016, p. 9). Exemplarian action research results in exemplary knowledge that can be used in comparable situations 
(Coenen \& Khonraad, 2003).

Exemplarian action research is divided into three stages: thematic, crystallization, and exemplarian (Coenen $\&$ Khonraad, 2003). In the thematic phase, researcher and participants formulate relevant themes for the research (Coenen $\&$ Khonraad, 2003). These themes should be in line with the daily practice of the researched. In the subsequent crystallization phase, an 'exemplar' is sought. This is a theme or themes that both researchers and researched view as the most important and central phenomenon. This offers a starting point for gaining insight and for practical improvement. A plan of action is drawn up. Thirdly, in the exemplary phase, the plan is tested and evaluated in practice.

\section{Data collection}

The three stages in this study were designed as presented in Table 1:

Table 1

Phasing research support-nets

\begin{tabular}{lll}
\hline $\begin{array}{l}\text { Stage } \\
\text { Thematic }\end{array}$ & $\begin{array}{l}\text { Activities } \\
\text { 16 in-depth interviews }\end{array}$ & $\begin{array}{l}\text { Respondents } \\
\text { Participants Support-net }\end{array}$ \\
\hline Crystallization & 4 Meetings & Research group: \\
& $\begin{array}{l}\text { Inventarisation themes } \\
\text { Inventarisation themes }\end{array}$ & 6 participants, 2 social workers \\
& Selecting options for improvement & \\
& Improvement plan & \\
\hline \multirow{2}{*}{ Exemplarian } & 2 meetings & Research group: \\
& Reflection on improvement plan & 6 participants, 2 social workers \\
& adjustments & \\
& Evaluation & \\
\hline
\end{tabular}

Before the start of the data collection, the research was approved by the management board of the social work organization. Institutional ethical review was not required for this study. Participants were protected in accordance with Dutch law, and all customary requirements of due care in scientific research were observed. Participants received written information about the study. This information was clarified orally by a social worker who was not affiliated with the Support-net. It was clearly explained that participation was voluntary and that participation could be discontinued at any time. The individuals who wished to participate signed a consent form.

The thematic stage consisted of 16 individual in-depth interviews. The respondents for the interviews were randomly selected. The only requirement was 
that the person was an active participant in the Support-net in Rotterdam at the time of the interview. The youngest participant interviewed was 42 years of age, the oldest 78. Eight of them were men, eight women. Twelve respondents were of Dutch background, and four were born in another country.

To conduct the individual interviews, a topic list was used. The interview focussed on the personal situation of the participants, their participation in the Support-net and their perception of the mutual support. Recordings were made of the interviews. These recordings were transcribed and coded with Atlas.ti. The topic list was a guideline for coding. This resulted in a comprehensive view of the life situations of the respondents and an extensive report on mutual support in Support-nets. This report was used as input for the following stages of the study.

For the following stages, a research group was formed, consisting of six participants, two social workers and the researcher/social worker. In selecting participants, the first prerequisite was that participation matched their abilities. For example, participants had to have sufficient concentration to attend the two-hour meetings. Secondly the ambition was to include participants for whom participation in the research would most likely be an empowering experience. This assessment was made by the researcher/social worker, together with a second social worker. Six people were selected, and all of them agreed to participate. The group came together for six meetings. The researcher prepared the meetings. Sound recordings were made of each meeting. They were used to prepare a detailed summary. This summary was presented orally to the participants for a member check, because written text would be difficult to comprehend for two participants.

The crystallization stage consisted of four meetings. In the first two meetings, the participants explored the themes that emerged from the interviews in more depth. The discussion in the research group complemented and enriched the data from the interviews. In the third meeting, the research group decided that it was desirable to elaborate on paper the methods that had hitherto been applied implicitly. In the fourth meeting they made a plan of action consisting of four points. In the first place, an outline for a written method description was made. In addition, sessions were planned to set up house rules, a procedure in the case of participant drop-out, and a competence profile for social workers.

In the exemplarian stage, a concept of method description was written and, after a member check, completed and published (Zwijnenburg, 2017). Another plan that was put into action was the development of a procedure in the event of a participant's dropout. Participants and social workers decided to work together to try to involve people again. In the third place, the research group drew up a competence profile that will be used in job interviews with social workers who want to work in a Support-net. The participants were clearly capable of identifying which characteristics they value in social workers.

In a discussion regarding house rules, it became clear that existing formats from other social work activities would not suffice. In existing formats, a lot of 
emphasis was placed on what was not allowed. The choice was made to formulate the house rules positively and to give people opportunities to participate and learn. An example house rule is: You can have your own opinion, but try to be careful not to impose it on others and try not to hurt others. The rule asks people to take into account each other's different opinions. The word 'try' indicates that the intention not to hurt each other is important, but at the same time it recognises that people can make mistakes.

The last meeting was an evaluation meeting, in which the research process was reflected upon. Both the social workers and the participants were positive about the research process. The study has strengthened the group identity of the Support-net and the partnership of participants with the social workers.

\section{Reflection on the position of the researcher}

In qualitative research, the researcher is personally involved (Maso and Smaling, 1998) and has to find a good balance between involvement and distance. This was a challenging aspect of this study, because the researcher worked as a social worker in the Support-net.

The position as social worker and researcher had both benefits and disadvantages. An advantage was that the participants already knew and trusted the social worker. As a result, they were willing to be open. On the other hand, the dual position carried the risk of bias. Because of this, the researcher made efforts to increase insight in the research process (Maso \& Smaling, 1998) of the research. She reflected on her role and the choices that were made in the research in a logbook.

Efforts were made to maximise validity by using different forms of data collection: interviews and focus group meetings. The interviews were analysed using Atlas.ti. The results of this analysis were given substance by joint reflection in the research meetings. 


\section{Results}

In this section the most important findings are categorized. Both the coded individual interviews and the summaries of the research group meetings are used to describe the results.

\section{Participants' backgrounds}

This part of the text focuses on the problems of the participants. It is important to keep in mind that each participant also has his or her own strengths and talents. Examples are: drawing, cooking, being hospitable, being able to listen well, handling a computer, and organizing.

The life history and living conditions of the participants were explored in the interviews. For most participants the seed for isolation was already laid in their youth. For example, participants were physically and mentally abused in their family of origin or they grew up in a family where there was little affection. From the personal histories it became clear that the participants experienced multiple adversities in their lives, which contributed to the lack of social support.

All respondents but two lived alone. Seven of them had never had a longterm relationship. Four respondents were separated after a problematic relationship. Three were widowed. For all respondents, contact with family was not as they would like it to be. Relations were problematic or one had less contact than one would have liked.

It is striking that seven of the respondents presently were, or had been, family carers. M. (56) lived her whole life together with her father. When he began to suffer from dementia she became his caretaker. She never left the house, except for doing groceries. She said, in looking back on her life,

I've never been married. Nothing I can do about it now. But I would have liked it, in hindsight though, yes I would have. (r10)

A participant who had been a family carer since adolescence had the experience that she herself could not count on the support of her family.

I always took care of my brothers, from 16 years old. Now I am ill myself but I don't see anyone. (r8)

Thirteen respondents had to deal with a mental illness, intellectual disabilities or brain damage. They noticed that there was little understanding for this in their social environment. J., who has experienced multiple psychotic episodes, said about this,

It is not nice when friends ask: 'What has become of you?' And then you have to tell that you are in a mental health institution. That creates stigma and then you are burning with shame. (r13) 
Most respondents had to make ends meet with little money. Some were in debt. Three male respondents had never had a large network. As long as they had a job, this was not a problem for them. When they became unemployed though, they were confronted with their lack of contacts in the private sphere, in combination with a lower income.

I never had any friends, didn't know anybody in Rotterdam. You know, I worked 50 hours a week, one and a half day at home. (r5)

\section{Insufficient network support}

In the interviews, all participants reported that they missed one or multiple types of social support (practical support, emotional support, companionship) in their network, before participating in the Support-network. Most participants became isolated after major life events, such as illness or loss of a loved one. Some of them have no contacts apart from the Support-net. This becomes painfully clear when the social workers, during the intake, want to note the name of someone they can call in case of an emergency. Some participants could not name a single person. However, in the interviews, when asked about loneliness (before participating in the Support-net), most of them said that it was not so bad. For example, B., who didn't have any contact with family or friends, said,

It is not a big problem, I think. No, I keep busy around the house, doing things. There is always stuff to do around the house. Or with my car, or my cat. (r16)

In a Research group meeting, participants admitted that they did experience feelings of loneliness, but that it was not easy to say that. It is less strenuous to say you are missing out on social support. According to them, the word loneliness should be avoided, especially when speaking with new potential participants. They proposed to use the term 'insufficient network support'.

\section{Contributing}

An important value of the Support-net is that participants are appreciated for what they can contribute. Every participant is enabled to participate actively. Being able to contribute makes participants feel valued again. M., who organizes a creative activity for others, said

You are precious. Yes... you get a warm reception. People say hey, we are ready to start.

This makes you feel appreciated. (r3) 
Another example is the 50-year-old W. He has been unemployed for years. Participation in the Support-net has ensured that he has a valuable social role again. He takes care of the groceries for the Support-net.

I decide for myself what should be bought...I buy what I think is necessary. What I want for the people.

The community-oriented activities, such as the baby clothes project, also gives people the feeling that their contribution matters. Pregnant women who receive clothes are encouraged by the social workers to send a postcard or to visit with their baby once it is born. In this way, a form of reciprocity is also strived for with the surrounding community.

\section{Group identity}

Participants have a sense of connection and they feel responsible for each other. They think about the activities and about reaching out to new participants or preventing dropout. They talk about 'our club' and 'our place'. There is a strong sense that you are there for each other. The Support-net is a place where people can have fun and they undertake activities together, but the participants also think along when a person has a problem or offer comfort if a person experiences something sad.

If I need something then I go there and then I can just ask: I need this or that... Or I can just come for a chat (r5)

There is a lot of freedom for people in the group. Participants are not obligated to attend weekly, but being part of the Support-net does mean that you are missed when you are not there. This means that a participant still shows up when he or she has a bad day.

Sometimes I thought I'm putting the blanket over my head and I'm staying in bed. But you don't because you know there are more people who have thoughts of staying in bed... Yes, and then you're really there for each other. (r10)

\section{Mutual relations and support}

Participants mentioned multiple examples of all three kinds of social support, emotional, instrumental, and companionship (Machielse, 2015). Because the Support-net does not focus on a particular disease or problem, the participants have different strengths. This makes a wide range of support available. 
In the individual interviews, people mainly mentioned examples of instrumental support they give to others, such as shopping for someone or accompanying someone to the hospital. This was further explored in the research group. It was observed that most participants both received and offered support. The reason that people talked less about received support is that they do not like to emphasize their weaknesses. Additionally, emotional support and companionship are offered so naturally that participants did not express it in words. In the research group, several examples emerged of how support is offered to each other in an everyday way from the personal, reciprocal relationship that participants build up with each other.

The point is that you make contact. That you go to someone and that you get a little closer to each other. If I say I like you, and you say I like you too, then you see what you can do together. (r7)

Participants choose for themselves how profound the relationships and the mutual support they give and receive are. Some keep it limited to contact in the community centre. Others also meet outside opening hours. The intensity of this varies from visiting each other for a cup of coffee, or accompanying someone to a hospital visit, to close friendships and love relationships. A., who met her friend J. through the Support-net, said,

He is my mate. We eat together, go out together. When I'm going fishing, he joins me.

When he has to go to hospital I accompany him. We are best friends. (r8)

Not every participant gives and receives the same amount of support, but this is not seen as a problem. It is okay as long as you try to contribute something. This can be limited to listening to another person's story or serving a cup of coffee to another person.

While there are a lot of good examples of mutual support, participants certainly do not always get along well. Conflicts regularly arise due to complex characters and limited social skills. Imbalance in relationships occurs, and well-intentioned support is not always experienced as such.

These situations require continuous attention from the social workers. They try to make sure that the participation remains comfortable for everyone. People are in general tolerant. Helpful in this regard is that participants mostly have an understanding for difficult behaviour of others, as long as the person brings something positive to the group. They realise that they have their weaknesses just like other participants. E., who swears a lot, said about this,

I don't mince my words and sometimes I get a little 'rough in my mouth' like they say it in Rotterdam, but it's OK here. (r14) 
Sometimes people are negatively affected by the behaviour of a specific person. The social workers address the person in that case. A lot of effort is made to keep a person in the group.

There are people who start meddling in something, not knowing what it's about. And then I'm like: Let them work it out. Don't interfere. (r6)

Nevertheless, it may happen that someone is no longer allowed to participate. This can be the case if the behaviour of the person puts the continuation of the group under pressure. The social workers are often stricter in this than the participants. They sometimes draw the line. There is always a search for another form of help for people who have to leave.

\section{Conclusion}

'It is not about being able to contribute a lot. It is about contributing what you are able to (Juan, member of the research group)

This research aimed to get insight into how participants, with the support of social workers, give substance to mutual support in the Support-net and how this helps them to overcome their social isolation. The above quote from one of the research group meetings, is illustrative of the working of the mutual support in Support-nets. The participants feel part of a group. They get to know each other as whole persons, with strengths and vulnerabilities. Every participant's (tailor-made) contribution is expected and appreciated in a Support-net. This provides a solid base from which reciprocal relationships and mutual support takes shape.

\section{Discussion}

Social isolation is defined in this study as a lack of social support. Therefore, overcoming this isolation implies an increase in the social support people receive from and give to others. The sense of belonging to a social group seems to be a prerequisite for the emergence of mutual support in a Support-net. Research in experimental social psychology (Frisch et al., 2014) shows that social support is only truly effective when provided by someone with whom the person shares a social identity. This would imply that social isolation can only really be overcome by enabling 
people to become part of a social group. MSGs have a great value here. Participating in a MSG leads to the feeling of connectedness with others (Cruwys et al., 2013) and makes participants feel that they belong to a social group (Finn, Bishop, \& Sparrow, 2009).

The importance of a shared social identity for the perception of social support has implications for social workers. They should focus on methods that offer people a sense of connectedness (Theurer et al., 2015). The importance of active participation to achieve this is a common thread throughout the data. By participating in a MSG, people become 'socially productive' (Siegrist, von dem Knesebeck, \& Pollack, 2004, p.1). Enabling participants to become socially productive is in lone with the empowerment perspective in social work in which participation is regarded as a powerful instrument (Van Regenmortel, 2009). For the participants in the Supportnet becoming socially productive means that they step out of an often long-term passive role and make a shift on the 'active-passive continuum' (Finn, Bishop, \& Sparrow, 2009, p.5).

In addition to being a remedy for socially isolated individuals, MSGs have a broader societal value. According to Rappaport (1993), people who participate in peer support organisations should be seen as people who form a community together. This is comparable to people who join a political party or a religious organisation. Thinking of an MSG as a community is interesting, because it would mean that participating provides an opportunity to reconnect the broken ties (Van Regenmortel, 2009) to society that socially isolated people experience. Further research is needed to explore whether these social worker-supported, relatively sheltered communities can function as a stepping stone for further connection to society.

There are a few comments to be made on how the study was carried out. In the first place, Only respondents who actively participated in the Support-net were selected to participate. Participants who have dropped out may have had a less positive opinion on the Support-net.

Secondly, this paper presents an intersubjective interpretation of the results, mutually agreed upon by researcher and researched. This has as a consequence that the results should not be seen as purely objective. However, they have an exemplary value (Coenen $\&$ Khonraad, 2003). At present, new Support-nets are being developed, based on the method description that was written alongside this study. This practice development is combined with a new cycle of action research for which a Community of Practice (Coyte et al., 2009), consisting of social workers, has been established. This follow-up research aims to gain insight in transferability of the method.

A second aim is to gain a better understanding of the position of the social workers in Support-net. We know that, due to the weak social skills of the participants, the continuous support of social workers is indispensable. In the research group though, the social workers spoke little about the work they do to contribute to the mutual support. Generally, social workers tend to underestimate 
their own role, because they want to emphasise the strength of the people they work for (Trappenburg, 2013). It is worthwhile to undertake more research into this, because enabling mutual support might be, according to Steinberg (2010) one of the best practices in social work.

\section{COVID-19 pandemic}

The study that this paper reports on was conducted before the outbreak of COVID-19. Although it is beyond the scope of this study, it is noteworthy to mention the impact of the pandemic on Support-nets.

During the first lockdown, which took place in the Netherlands in March 2020, community centres were closed. This meant that the activities of the three current Support-nets could not continue. The social workers noticed that many participants continued to support each other outside of the activities. For example, they made arrangements to go for a walk together, or came up with plans to do crafts together. Group-apps were set up in which participants were in touch with each other on a daily basis. As soon as it was possible, the participants met again in small groups at the community centre. It was striking that the lockdown did not lead to any drop-out of participants.

The lack of opportunities for lonely people to have contact with others, led to very painful situations for the most vulnerable residents throughout the country. During the second lockdown, which is in effect at the time of writing (January 2021), it was therefore decided to keep the community centres open as a meeting place for the most lonely and most vulnerable neighborhood residents. The importance of community-oriented social work is thereby acknowledged. We see this as a positive development for the profession of social work.

\section{References}

Almekinders, C., Beukema, L. \& Tromp, C. (Eds.) (2009) Research in Action: Theories and practices for innovation and social change, Mansholt Publication Series, Wageningen

Ten Bruggencate, T., Luijkx, K. G. \& Sturm, J. (2018) Social needs of older people: A systematic literature review. Ageing \& Society, 38, 9, 1745-1770

Coenen, H. \& Khonraad, S. (2003) Inspirations and aspirations of exemplarian action research. Journal of Community \& Applied Social Psychology, 13, 439-450

Coumans, M. (2016) Sociale isolatie. Naar objectieve en subjectieve maatstaf [Social isolation. By objective and subjective standards], CBS, [Online] Available at: https://www.cbs.nl/-/ media/_pdf/2016/50/sociale-isolatie.pdf 
Coyte, P., Nielsen, C., Judd, M., Grimshaw, J., Li, L., \& Graham, I. (2009). 'Evolution of Wenger's concept of community of practice. Implementation Science; vol. 4, 1

Cruwys, T., Dingle, G. A., Haslam, C., Haslam, S. A., Jetten, J. \& Morton, T. A.(2013) Social group memberships protect against future depression, alleviate depression symptoms and prevent depression relapse. Social Science $\&$ Medicine, 98, 179-186

Deacon, L., Macdonald, S. J., Nixon, J., Akintola, A. R., Dore, S., Ellis, G., Gillingham, A., Highmore, L., Ismail, A., Kent, J., Matthews, D. and Sullivan, S. (2019) The loss: conceptualising biographical experiences of disability, social isolation and emotional loneliness in North-East England. Social Work and Social Sciences Review, 20, 3, 68-87. doi: 10.1921/swssr.v20i3.1319

Dickens, A.P., Richards, S.H., Greaves, C.J. \& Campbell, J.L. (2011) Interventions targeting social isolation in older people: A systematic review. BMC Public Health. [Online] Available at: https://bmcpublichealth.biomedcentral.com/articles/10.1186/1471-2458-11-647

Elishia, D., Casting, D. \& Hocking, B. (2006) Reducing social isolation in people with mental illness: The role of the psychiatrist. Australassian Psychiatry, 14, 481-484

Finn, L.D., Bishop, B.J. \& Sparrow, N. (2009) Capturing dynamic processes of change in GROW mutual help groups for mental health. American Journal of Community Psycology; vol. 44, 3-4, 302-315

Frisch, J.U., Hauser, J.A., van Dick, R. \& Mojzisch, A. (2014) Making support work: The interplay between social support and social identity. Journal of Experimental Social Psychology, 55, 154-161

Holt-Lunstad, J., Smith, T.B., Baker, M., Harris, T. \& Stephenson, D. (2015) Loneliness and social isolation as risk factors for mortality: A meta-analytic review. Perspectives on Psychological Science; vol 10, 2, 227-237

Hortulanus, R.P., Machielse A. \& Meeuwesen, L. (2003) Sociaal isolement. Een studie over sociale contacten en sociaal isolement in Nederland,. [Social isolation. A study on social contacts and social isolation in the Netherlands]. The Hague: Elsevier Overheid

Julkunen, I. (2011). Critical elements in evaluating and developing practice in social work: An exploratory overview. Social work ESocial Sciences Review, 15, 1, 74-91

Kessler, D., Egan, M. \& Kubina, L.A. (2014). Peer support for stroke survivors: A case study. BMC Health Serv Res, 14, 256

LeCroy, C. W. (ed) (2014) Case Studies in Social Work Practice. (3rd ed.) Hoboken, NJ : John Wiley

Linders, L. (2010). De betekenis van nabijheid: Een onderzoek naar informele zorg in een volksbuurt [The significance of proximity: A study of informal care in a working-class neighbourhood] The Hague: SDU-uitgevers

Linehan, T., Bottery, S., Kaye, A., Millar, L., Sinclair, D. \&amp; Watson, J. (2014) 2030 Vision: The best and worst futures for older people in the UK. London : Independent Age and international Longevity Centre-UK

Machielse, A. (2006). Onkundig en onaangepast. Een theoretisch perspectief op sociaal isolement [Unknowing and inappropriate. A theoretical perspective on social isolation]. Utrecht: Van Arkel 
Machielse, A. (2015) The heterogeneity of socially isolated older adults: A social isolation typology. Journal of Gerontological Social Work, vol,58, no.4, 338-356

Maso, I. \& Smaling, A. (1998). Kwalitatief onderzoek. Praktijk en theorie. [Qualitative research, Practice and theory] Amsterdam: Boom

Nicolaisen, M. \& Thorsen, K. (2014) Who are lonely? Loneliness in different age groups (18-81 years old), using two measures of loneliness. International journal aging and human development, 78, 3, 229-257

Rappaport, J. (1987) Terms of empowerment/exemplars of prevention. Toward a theory for community psychology. American Journal of Community Psychology, 15, 2, 121-148

Rappaport, J. (1993) Narrative studies, personal stories, and identity transformation in the mutual help context. The Journal of Applied Behavioral Science, 29, 2, 239-256

Regenmortel, T. van. (2009) Empowerment als uitdagend kader voor sociale inclusie en moderne zorg [Empowerment as a challenging framework for social inclusion and modern care.], Journal of Social Intervention: Theory and practice; vol. 18, 4, 22-42

Regenmortel, T. van. (2016) Empowerment onderzoek. Een kritische vriend voor sociaal werkers [Empowerment research. A critical friend for social workers]; Journal of Social Intervention: Theory and Practice, 25, 3, 4-23

Schutt, R. K. \& Rogers, E. S. (2009) Empowerment and peer support: Structure and process of self-help in a consumer-run center for individuals with mental illness. Journal of Community Psychology, 37, 6, 697-710

Siegrist, J., von dem Knesebeck, O. \& Pollack, E. (2004)' Social productivity and well-being of older people: A sociological exploration. Social Theory \& health; vol. 2, 1, 1-172

Solomon, P. (2004) Peer support/peer provided services. Underlying processes, benefits, and critical ingredients. Psychiatric rehabilitation journal, 27, 4, 392-401

Steinberg, D.M. (2010) Mutual aid: A contribution to best-practice social work. Social Work with Groups, 33, 1, 53-68

Theurer, K., Mortenson, W.B., Stone, R., Suto, M., Timonen, V. \& Rozanova, J. (2015) The need for a social revolution in residential care. Journal of Aging Studies, 35, 201-210

Trappenburg, M (2013) Bescheiden professies Over evidence based werken buiten de cure' [Modest professions About evidence-based working outside the cure], CEG, [Online] Available at: https://ceg.nl/uploads/publicaties/Tweede_Els_Borst_Lezing.pdf

Uehara, E. S. (1995) Reciprocity reconsidered: Gouldner's ‘moral norm of reciprocity’ and social support. Journal of Social and Personal Relationships, 12, 4, 483-502

Van de Westenlaken, A. (2012) Maatwerk bij de aanpak van eenzaamheid. 41 Interventies [Tailor-made approach to loneliness. 41 interventions] Tilburg: BVWO

Zwijnenburg, J. (2017) Methodebeschrijving Vangnetwerken [Method Description Supportnets.]. Tilburg :Tranzo 